\title{
Desechos orgánicos que generan gas a través de un biodigestor diseño experimental en la parroquia Guasaganda de la ciudad de la Maná @)(1)
}

\author{
Organic waste that generates gas through a biodigestor experimental design \\ in the Guasaganda parish of the city of Maná
}

Recibido: 22-03-2019 / Revisado: 27-04-2019 /Aceptado: 26-05-2019/ Publicado: 05-06-2019

Ing. MSc. William Armando Hidalgo Osorio ${ }^{1}$, Ing. MSc. Paco Jovanni Vásquez Carrera ${ }^{2}$, Ing. MSc. Kleber Augusto Espinosa Cunuhay ${ }^{3}$, P.hD. Yoandrys Morales Tamayo ${ }^{4}$,

\begin{abstract}
.
DOI: https://doi.org/10.33262/cienciadigital.v3i2.6.558

In this research, a study will be carried out on how to use organic waste to prevent it from becoming a source of infection. In small-scale agriculture and livestock, waste has been treated to transform it into natural fertilizers, and in some cases as fuel. Biodigesters are natural systems that take advantage of organic waste, from agricultural activities, mainly manure, to produce biogas (fuel) and biol (natural fertilizer) through the process of anaerobic digestion. Biogas can be used as fuel in kitchens, heating or lighting. In large facilities, biogas can be used to power an engine that generates electricity. The fertilizer, called biol, has initially been considered a secondary product, but is currently being treated with the same or greater importancethan biogas, since it provides families with a natural fertilizer that strongly improves the yield of the crops. There are several types of biodigesters, but this proposal presents low-cost biodigesters, which are those that do not require active heating systems and / or mobile mixing mechanisms. In this way, low-cost biodigesters are considered an appropriate technology because of their low investment cost, because they are easy to use, require little maintenance and are accessible to small producers as well as large ones. The incidence of family biodigesters is not only highlighted by the generation of renewable and cheap energy, but also benefits family health, because biogas does not give off smoke when cooking.
\end{abstract}

\footnotetext{
${ }^{1}$ Universidad Técnica de Cotopaxi, Ecuador, william.hidalgo7885@utc.edu.ec

${ }^{2}$ Universidad Técnica de Cotopaxi, Ecuador, paco.vasquez@utc.edu.ec

${ }^{3}$ Universidad Técnica de Cotopaxi, Ecuador, kleber.espinosa@utc.edu.ec

${ }^{4}$ Universidad Técnica de Cotopaxi, Ecuador, yoandrys.morales@utc.ed.ec
} 
Keywords: Biodigesters, natural systems, biogas, anaerobic digestion, natural fertilizer, renewable energy.

\section{Resumen}

En esta investigación se realizará un estudio de cómo aprovechar residuos orgánicos y así evitar que se conviertan en un foco de infección. En la agricultura y ganadería a pequeña escala se ha venido tratando los residuos para transformarlos en abonos naturales, y en algunos casos como combustible. Los biodigestores son sistemas naturales que aprovechan residuos orgánicos, procedentes de actividades agropecuarias, principalmente estiércol, para producir biogás (combustible) y biol (fertilizante natural) mediante el proceso de digestión anaerobia. El biogás puede ser empleado como combustible en las cocinas, calefacción o iluminación. En grandes instalaciones se puede utilizar el biogás para alimentar un motor que genere electricidad. El fertilizante, llamado biol, inicialmente se ha considerado un producto secundario, pero actualmente se está tratando con la misma importancia, o mayor, que el biogás, ya que provee a las familias de un fertilizante natural que mejora fuertemente el rendimiento de las cosechas. Existen diversos tipos de biodigestores, pero en esta propuesta se presentan los biodigestores de bajo costo, que son aquellos que no requieren de sistemas activos de calefacción y/o mecanismos móviles de mezcla. De esta manera los biodigestores de bajo costo se consideran una tecnología apropiada por su bajo coste de inversión, por su fácil manejo, por requerir poco mantenimiento y por ser accesible a los pequeños productores como a los grandes. La incidencia de biodigestores familiares no solo se destaca por la generación de energía renovable y barata, sino que también beneficia a la salud familiar, porqué el biogás no desprende humo al cocinar.

Palabras Claves: Biodigestores, Sistemas naturales, biogás, digestión anaerobia, fertilizante natural, energía renovable.

\section{Introducción.}

Según Gallo Mendoza, 2016 y Rodriguez \& Urbina Bravo, 2013 Nuestro país cuenta con una amplia variabilidad climática, posee climas: subtropicales, templados y fríos. En cuanto a la cuestión socio ambiental agropecuaria, en general no hay acceso a las redes de distribución de energía (tanto eléctrica -con mayor desarrollo- como gas), asimismo las explotaciones en la escala de Agricultura Familiar (entre pequeños y medianos productores) abarcan un $60 \%$ del total nacional, además hay poblaciones dispersas y empresas procesadoras de alimentos de pequeña escala. Al presente, la respuesta en la temática gasífera es escasa, con esfuerzos de instituciones privadas y gubernamentales, que en general transcurren en el autoconstrucción de biodigestores de mampostería del tipo hindú, que una vez construidos no presentan variaciones en su empleo y capacidad operativa; además hay 
experiencias de construcciones en plástico rígido y flexible (tubular y geo membrana). Las alternativas de construcción "llave en mano" realizada por empresas, se tornan onerosas para grupos de productores pequeños, tanto para uso familiar como espacios comunitarios y agroindustria.

Comentario: Los biodigestores familiares de bajo costo son sistemas naturales que aprovechan el estiércol del ganado para producir biogás y biol. El biogás es un gas con alto porcentaje en metano que puede ser empleado en una cocina convencional sustituyendo a la leña o GLP. Este biogás también puede ser empleado en lámparas de gas para iluminación. El biol es un fertilizante ecológico que puede emplearse directamente en la fertilización de los o decantarlo para obtener fertilizante foliar, de esta forma no se pierde la capacidad fertilizante del estiércol que es de uso común en el ámbito rural.

Estos sistemas se han introducido en Ecuador en el año 2005 como un proyecto piloto de tecnología apropiada según CEDECAP, 2017 y Marti Herrero, 2014 dice que es asequibles todos los materiales en el mercado local ecuatoriano, con un bajo costo de inversión y con un fácil manejo y mantenimiento, que no requiere de técnicos, ya que la propia familia participa y es capacitada durante la instalación. Desde entonces, más de 320 biodigestores fueron instalados por diferentes instituciones. La tecnología se fue desarrollando para abarcar todas las regiones.

Entre los beneficios ecológicos, es importante mencionar la reducción de la deforestación debida a consumo de leña para cocinar. También se evita contaminación por la sustitución de los agroquímicos y se administra un buen manejo de residuos ganaderos, que, en casos de alta densidad, pueden llegar a contaminar acuíferos. Al disponer de un fertilizante de producción propia, el mismo terreno rinde más, y de este modo se evita la ampliación de frontera agrícola. Finalmente, al tener en cuenta el efecto invernadero y el cambio climático, se capturan las emisiones de gas metano en el biodigestor, que de otro modo irían a la atmosfera. Baste recordar que el metano incide negativamente sobre el cambio climático 23 veces más que el dióxido de carbono.

Arce Cabrera, 2011 y Casera, 2009 manifiesta que el biogás es un producto del metabolismo de las bacterias metanogénicas que participan en la descomposición de tejidos orgánicos en ambiente húmedo y carente de oxígeno. A su vez, durante el proceso de descomposición, algunos compuestos orgánicos son transformados a minerales, los cuales pueden ser utilizados fácilmente como fertilizantes para los cultivos. La producción de biogás va a depender, principalmente, de los materiales utilizados, de la temperatura y del tiempo de descomposición. Lo anteriormente descrito corresponde a un proceso de descomposición anaeróbica, donde se puede obtener entre otros, etanol, metanol y gas metano, no así en un proceso de descomposición aeróbica. 
Comentario: Esta propuesta proporcionará información de cómo construir un biodigestor en una zona tropical, en estas condiciones ambientales el tiempo de retención (tiempo necesario para producir biogás) es relativamente elevado y puede afectar la viabilidad del proyecto si no se toma en cuenta los sistemas necesarios. También está el reto de adecuar el biodigestor en una familia a partir de biomasa residual generada por los animales domésticos y desechos orgánicos, haciendo que el sistema planteado sea plenamente seguro y confiable para las personas que interactúen con él.

\section{BIODIGESTORES FAMILIARES.}

\section{Historia del Biodigestor}

Según las literaturas de Rodriguez Pichon \& Garcia Cepeda, 2017 nos manifiesta que primeras menciones sobre biogás se remontan al año $1.600 \mathrm{DC}$, identificados por varios científicos como un gas proveniente de la descomposición de la materia orgánica. En el año 1890 se reporta la construcción del primer Biodigestor a escala real en la India y ya en 1896 en Exeter, Inglaterra, las lámparas de alumbrado público eran alimentadas por el gas recolectado de los digestores que fermentaban los lodos cloacales de la ciudad. Tras las guerras mundiales comienza a difundirse en Europa las llamadas fábricas productoras de biogás cuyo producto se empleaba en tractores y automóviles de la época.

En todo el mundo se difunden los denominados tanques "Imhoff" para el tratamiento de aguas cloacales colectivas. El gas producido se lo utilizó para el funcionamiento de las propias plantas, en vehículos municipales y en algunas ciudades se lo llegó a inyectar en la red de gas comunal. Durante los años de la segunda guerra mundial comienza la difusión de los biodigestores a nivel rural tanto en Europa como en China e India que se transforman en líderes en la materia. Esta difusión se ve interrumpida por el fácil acceso a los combustibles fósiles y recién en la crisis energética de la década de los años 70 se reinicia con gran ímpetu la investigación y extensión en todo el mundo incluyendo la mayoría de los países latinoamericanos.

Los últimos 20 años han sido fructíferos en cuanto a descubrimientos sobre el funcionamiento del proceso microbiológico y bioquímico gracias al nuevo material de laboratorio que permitió el estudio de los microorganismos intervinientes en condiciones anaeróbicas (ausencia de oxígeno). Estos progresos en la comprensión del proceso microbiológico han estado acompañados por importantes logros de la investigación aplicada, obteniéndose grandes avances en el campo tecnológico.

Los países generadores de tecnología más importantes en la actualidad son: China, India, Holanda, Francia, Gran Bretaña, Suiza, Italia, EE.UU., Filipinas y Alemania, cuyas plantas de tratamiento de desechos industriales, han tenido una importante evolución habiendo superado una primera etapa a nivel piloto, a lo largo de los años transcurridos, la tecnología de la digestión anaeróbica se fue especializando abarcando actualmente muy diferentes 
campos de aplicación con objetivos muy diferentes, siendo difundidas para determinados fines en combinación con tratamientos aeróbicos convencionales.

Estos reactores anaeróbicos son de enormes dimensiones (más de $1.000 \mathrm{~m} 3$ de capacidad), trabajan a temperaturas termofílicas $\left(20^{\circ} \mathrm{C} \mathrm{a} 40^{\circ} \mathrm{C}\right)$, poseen sofisticados sistemas de control y están generalmente conectados a equipos de cogeneración, que brindan como productos finales; calor, electricidad y un efluente sólido de alto contenido proteico, para usarse como fertilizante o alimento de animales. A nivel latinoamericano, se ha desarrollado tecnología propia en la Argentina para el tratamiento de vinazas, residuo de la industrialización de la caña de azúcar. En Brasil y Colombia se encuentran utilizando sistemas europeos bajo licencia (Asamblea Nacional República del Ecuador, 2014)

Acuña Rubio, 2015 manifiesta que la incidencia de los biodigestores familiares de bajo costo no sólo es destacable por la generación de energía barata (biogás), y la producción de un fertilizante ecológico (biol), sino que también incide directamente sobre la salud familiar, al sustituir la leña para cocinar por un gas que no desprende humo en la cocina, tan dañino a las vías respiratorias, sobre todo para las mujeres.

La carga de trabajo físico que conlleva la búsqueda de leña se ve reducida, especialmente en mujeres y niños. A nivel medioambiental, la carga de estiércol diario del biodigestor elimina moscas y olores, además de reducir enfermedades del ganado como la mastitis

Comentario: Un biodigestor, es básicamente un simple es un contenedor cerrado, hermético e impermeable. Dentro del cual se introduce materia orgánica como desechos vegetales o frutales (Excluyendo a los cítricos ya que acidifican el medio); a su vez, materia que segregue bacterias, proveniente de la carne en descomposición o excremento de animales, avícolas y/o humanos, dentro de una disolución con agua. Por lo tanto, esta mezcla, mediante la fermentación anaeróbica de los microorganismos, es degradada obteniendo como producto biogás. También se puede obtener un subproducto líquido, denominado Biol, el cual puede ser utilizado como fertilizante.

\section{Concepto, ventajas y aplicaciones de los biodigestores.}

\section{Biodigestor.}

Un biodigestor está formado por un tanque hermético donde ocurre la fermentación y un depósito que sirve para el almacenaje de gas. Las dos partes pueden estar juntas o separadas y el tanque de gas puede ser de campana fija o flotante. En el caso del biodigestor de polietileno, el tanque de digestión y de recolección de gas, conforman uno sólo. El proceso de digestión ocurre en la parte inferior del recipiente, y en la parte superior se colecta el gas. 


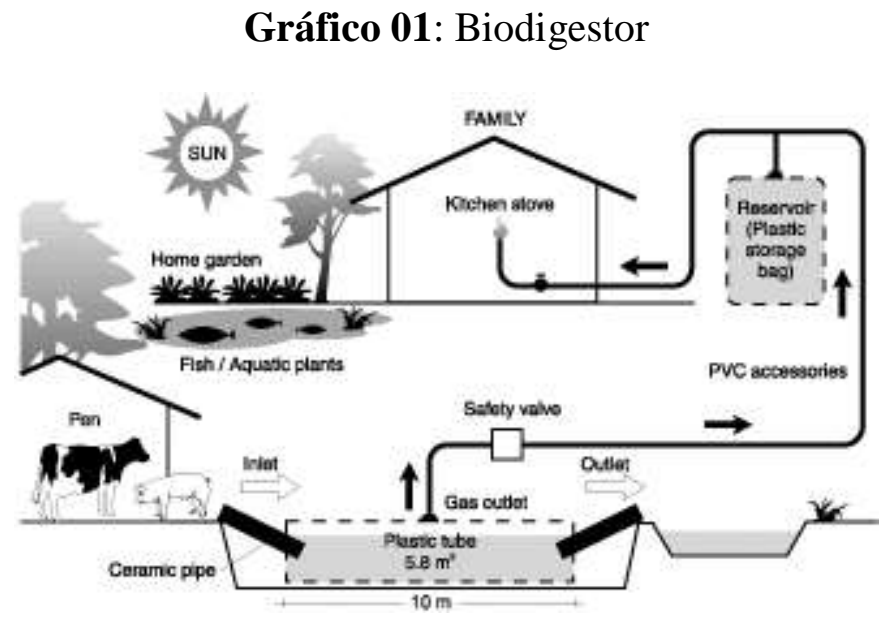

Referencia: http://biogas-dah-cx.blogspot.com/p/los-biodigestores-familiares-debajo.html

El esquema superior es un dibujo del perfil de un biodigestor para tener una idea básica de s u concepto.

- Tubería de entrada del biodigestor.

- Tubería de salida del biodigestor

- Tanque donde se va a digerir la mezcla de agua y estiércol.

- Cámara de colección de gas.

- Tubería de salida del gas.

- Recipiente de entrada para la carga

- Recipiente de recolección de Biol.

Este biodigestor, posee una tubería de entrada a través del cual se suministra la materia orgánica (por ejemplo, estiércol animal o humano, las aguas sucias de las ciudades, residuos de matadero) en forma conjunta con agua, y una tubería de salida en el cual el material ya digerido por acción bacteriana abandona el biodigestor. Los materiales que ingresan y abandonan el biodigestor se denominan afluente y efluente respectivamente.

El proceso de digestión que ocurre en el interior del biodigestor libera la energía química contenida en la materia orgánica, la cual se convierte en biogás.

La duración de la reducción del material biológico depende de los microorganismos especiales y de sus temperaturas óptimas del crecimiento.

Los principales componentes del biogás son el metano $(\mathrm{CH} 4)$ y el dióxido de carbono $(\mathrm{CO} 2)$. Aunque la composición del biogás varía de acuerdo a la biomasa utilizada, s u composición aproximada se presenta a continuación (Werner et al 1989): 
Metano

Dióxido de carbono

Sulfuro de hidrógeno

Hidrógeno
$\mathrm{CH} 440-70 \%$ volumen

$\mathrm{CO} 230-60$

$\mathrm{H} 2 \mathrm{~S} 0-3$

$\mathrm{H} 20-1$

El metano, principal componente del biogás, es el gas que le confiere las características combustibles al mismo, un combustible bastante limpio eficiente que puede ser utilizado directamente. El valor energético del biogás por lo tanto estará determinado por la concentración de metano - alrededor de 20 - $25 \mathrm{MJ} / \mathrm{m} 3$, comparado con 33 - 38MJ/m3 para el gas natural (Werner et al 1989).

Por otro lado, los residuos de la fermentación (efluentes), contienen una alta concentración de nutrientes y materia orgánica, lo cual los hace susceptibles de ser utilizados como un excelente fertilizante que puede ser aplicado en fresco, ya que el proceso de digestión anaerobia elimina los malos olores y la proliferación de moscas. Otra ventaja es la eliminación de agentes patógenos presentes en las heces, lo cual significa que el efluente líquido puede ser utilizado para regadío de cualquier tipo de cultivos.

\section{Características del Digestor}

Para una buena operación, es necesario que el digestor reúna las siguientes características:

- Hermético, para evitar fugas del biogás o entradas de aire.

- Térmicamente aislado, para evitar cambios bruscos de temperatura.

- El contenedor primario de gas deberá contar con una válvula de seguridad.

- Deberán tener acceso para mantenimiento.

- Deberá contar con un medio para romper las natas que se forman.

\section{Procesos bioquímicos de la Biodigestión anaerobia:}

La materia orgánica contenida en los desechos, bajo ciertas condiciones, es posible que sea tratada biológicamente por acción de microorganismos, en recipientes herméticamente sellados.

Este es un proceso de fermentación en ausencia de oxígeno, donde se genera na mezcla de gases que, en s u conjunto, reciben el nombre de biogás.

Básicamente, el proceso considera tres etapas: Hidrólisis, etapa en la que los polisacáridos (celulosa, almidón, etc.), los lípidos (grasas) y las proteínas, son reducidas a moléculas más simples; Acidogénesis, etapa en que los productos formados anteriormente son 
transformados principalmente en ácido acético, hidrógeno y CO2; Metanogénesis, los productos resultantes de esta etapa son metano $\mathrm{CH} 4$ y $\mathrm{CO} 2$, principalmente.

Considerando que las bacterias son el ingrediente esencial del proceso, es necesario mantenerlas en condiciones que permitan asegurar y optimizar s u ciclo biológico. Los principales parámetros que influyen en la producción de biogás son:

- Temperatura

- Tiempo de Retención

- Relación Carbono/Nitrógeno

- Porcentaje de sólidos

- $\mathrm{pH}$ :

- Agitación

\section{Biogás.}

El biogás es el gas producido durante el proceso de fermentación anaerobia (sin presencia de oxígeno) de la fracción orgánica de los residuos. Está compuesto principalmente por Metano (CH4) y Dióxido de Carbono (CO2), además de otros gases en cantidades menores.

Cuando los desechos orgánicos inician el proceso químico de fermentación (pudrimiento), liberan una cantidad de gases llamados biogás. Con tecnologías apropiadas, el biogás se puede transformar en otros tipos de energía, como calor, electricidad o energía mecánica.

\section{Tipos.}

De acuerdo a la frecuencia de cargado, los sistemas de Biodigestión se pueden clasificar en:

Batch o discontinuo. - se carga una sola vez en forma total y la descarga se efectúa una vez que ha dejado de producir gas combustible. Normalmente consiste en tanques herméticos con una salida de gas conectada a un gasómetro flotante, donde se almacena el biogás. Este sistema es aplicable cuando la materia a procesar está disponible en forma intermitente.

Semi continuos. - Es el tipo de digestor más usado en el medio rural, cuando se trata de digestores pequeños para uso doméstico. Los diseños más populares son el hindú y el chino. Poseen el gasómetro integrado al sistema y se construyen totalmente enterrados. Se cargan por gravedad una vez al día, con un volumen de mezcla que depende del tiempo de fermentación o retención y producen una cantidad diaria más o menos constante de biogás si se mantienen las condiciones de operación.

Continuos. - Este tipo de digestores se desarrollan principalmente para tratamiento de aguas residuales. En general son plantas muy grandes, en las cuales se emplean equipos comerciales para alimentarlos, proporcionarles calefacción, agitación, así como para s u control. 


\section{VENTAJAS DEL USO DE BIODIGESTORES:}

\section{Relacionadas con el medio ambiente.}

- Reducción de la producción de gas metano. El excremento en estado natural expulsa grandes cantidades al espacio de este gas, que es uno de los más perjudiciales para la capa de ozono.

- Evita los malos olores entre el 90 y $100 \%$.

- Se evita la contaminación de suelos y agua. Los excrementos constituyen uno de los elementos más contaminantes de nuestro medio ambiente.

- Se evita la tala de árboles para ser utilizados como combustible. Los biodigestores son una de las grandes posibilidades para evitar la tala desmedida.La producción de fertilizante orgánico; es una opción para cambiar la agricultura tradicional por una orgánica, el afluente del biodigestor es una excelente alternativa.

- No se produce humo; este es uno de los males que afectan la salud de las mujeres del campo.

- Permite un manejo adecuado de los desechos.

- No se da la proliferación de insectos.

\section{Asociado con el bienestar familiar.}

- Se evita el hollín de los trastos, techo y toda la casa, cuando se cocina con leña es inevitable, la familia tiene que construir una cocina aparte de la casa para evitar los efectos del humo. Además, debe invertir para la reposición de trastos y techo para s u casa, lo que se traduce en un gasto económico.

- La búsqueda de leña se reduce, por tanto, se aminora o se suprime este trabajo en mujeres y niños.

- No hay peligro de explosiones, el cilindro de gas tradicional siempre es un peligro constante; el biodigestor nunca podrá ser una amenaza dentro de una casa.

- Mejora la economía familiar.

- Es muy rápido para cocinar. Este gas tiene una llama azul con una alta concentración de calor, lo que facilita una cocción rápida.

- El fuego del biodigestor se prende solo cuando se requiere de el. En el caso de cocinas con leña, ésta debe estar todo el día prendida y supone peligros.

- Cualquier miembro de la familia puede colaborar en la preparación de los alimentos por las ventajas que tiene el gas del biodigestor en la casa.

- Las reparaciones del biodigestor son sencillas. Cuando se tiene un conocimiento mínimo de cómo manejarlo, se puede realizar sin problemas.

- Es una inversión de bajo costo para la familia; muchos materiales los puede obtener de s u finca y gran parte de la mano de obra la aporta la familia y el técnico sólo debe ofrecer la asesoría. 
- Es una inversión para muchos años. Según datos, los materiales utilizados en la construcción del biodigestor, dependiendo del tipo de sistema, garantizan que será una actividad que dura desde 2 años en el caso de polietileno, hasta 30 años y más en construcciones de material noble.

- El mantenimiento es de bajo costo. En lo que puede tener problemas es con el plástico y éste se puede cambiar o reparar sin mucha inversión de dinero.

\section{Aplicaciones.}

A pequeña y mediana escala, el biogás ha sido utilizado en la mayor parte de los casos para cocinar en combustión directa en estufas simples. Sin embargo, también puede ser utilizado para iluminación, para calefacción y como reemplazo de la gasolina o el combustible diésel en motores de combustión interna.

La utilización de los biodigestores además de permitir la producción de biogás ofrece enormes ventajas para la transformación de desechos:

Mejora la capacidad fertilizante del estiércol. Todos los nutrientes tales como nitrógeno, fósforo, potasio, magnesio, así como los elementos menores son conservados en el efluente. En el caso del nitrógeno, buena parte del mismo, presente en el estiércol en forma de macromoléculas es convertido a formas más simples como amonio (NH4+), las cuales pueden ser aprovechadas directamente por la planta. Debe notarse que en los casos en que el estiércol es secado al medio ambiente, se pierde alrededor de un 50\% del nitrógeno.

- El efluente es mucho menos oloroso que el afluente.

- Control de patógenos.

- Control de malos olores

- El efluente puede ser utilizado como alimento para peces, en lagos o estanques artificiales, además de la lombricultura.

- Un metro cúbico de biogás totalmente combustionado es suficiente para:

- Generar $1.25 \mathrm{kw} / \mathrm{h}$ de electricidad.

- Generar 6 horas de luz equivalente a un bombillo de 60 watt.

- Poner a funcionar un refrigerador de $1 \mathrm{~m} 3$ de capacidad durante 1 hora.

- Hacer funcionar una incubadora de $1 \mathrm{~m} 3$ de capacidad durante 30 minutos.

- Hacer funcionar un motor de 1 HP durante 2 horas.

\section{RESULTADOS.}

Para el diseño del biodigestor de polietileno, deberán tomarse en cuenta los siguientes criterios:

- Necesidades de biogás. Tiempos a usarse en cocción o en iluminación.

- Necesidades de biol. Cantidad de fertilizante foliar requerido.

- Necesidades medioambientales. Tipo de problema ambiental a solucionar 
- Límite de materia prima. Cantidad de estiércol a tratar diariamente.

\section{Cálculo de cantidad de estiércol:}

\begin{tabular}{llll}
\hline Animal & $\begin{array}{l}\text { Estiércol } \\
\text { (Kg./100 kg. De } \\
\text { peso vivo) }\end{array}$ & $\begin{array}{l}\text { Peso } \\
\text { animal } \\
(\mathrm{Kg} .)\end{array}$ & $* \begin{array}{l}\text { Estiércol } \\
\text { diario } \\
(\mathrm{kg} .)\end{array}$ \\
\hline Vaca & 8 & 400 & 32 \\
Cerdo & 4 & 70 & 2.8 \\
cabra & 4 & 60 & 2.4 \\
caballo & 7 & 350 & 24.5 \\
\hline
\end{tabular}

Tabla 1.1: Estiércol disponible por tipo de animal

La cantidad de estiércol disponible depende del manejo del ganado en la zona, para el caso de ganado tabulado, el total de estiércol a aprovechar es del $100 \%$ y en el caso de ganado tabulado sólo por la noche, el estiércol a aprovechar es del $25 \%$.

\section{Materia a digerir.}

Para obtención de biogás: La mezcla de estiércol y agua deberá ser de 1:4.

Para la obtención de biol primordialmente: La mezcla deberá ser 1:3

Ejemplo 1:

En el caso de tener 2 vacas y un cerdo, los cálculos según Tabla 1.1:

Tipo de animal Peso Kg. Cant. De estiércol (Kg.)/ día

\begin{tabular}{lll}
\hline Vaca & 350 & 56 \\
cerdo & 70 & 2.6 \\
\hline
\end{tabular}

Total: 58.6

En este caso, considerando mezcla de 1:4, la materia a digerir por día sería: $(58.6$ x $4=23.4)$; 58.6 de estiércol y 23.4 lts de agua.

\section{Tiempo de retención:}

Es el tiempo que transcurre entre la carga y descarga del sistema. La velocidad de degradación depende en gran parte de la temperatura ambiente, pues a mayor temperatura el tiempo de retención requerido es menor. 
Tabla 1.2: Tiempos de Retención (TR)

\begin{tabular}{ll}
\hline Temperatura ${ }^{\circ} \mathrm{C}$ & Día \\
\hline 10 & 55 \\
20 & 25 \\
30 & 10 \\
\hline
\end{tabular}

\section{Instalación Del Biodigestor}

Se puede construir un biodigestor anaeróbico casero a partir de un bidón o tanque de polietileno con capacidad entre 120 y 220 litros. No se necesitan grandes conocimientos técnicos ni materiales difíciles de conseguir para su construcción; solo observe la imagen, lea los materiales y lo comprenderá. El diseño propuesto es bastante común, y al ser semicontinuo permite adicionar residuos orgánicos diariamente.

Gráfico 02: Instalación del biodigestor

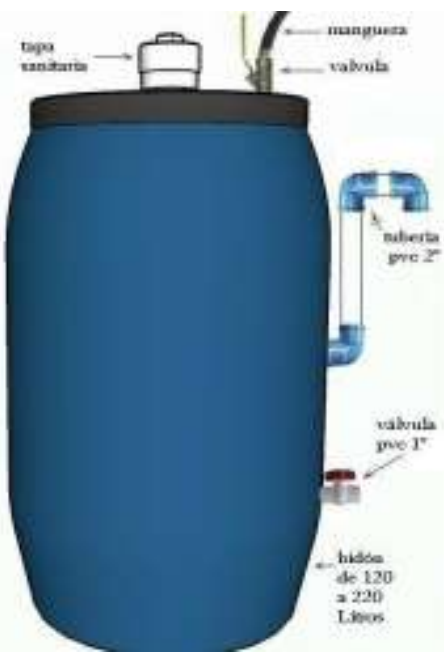

Referencia: http://www.pregonagropecuario.com/cat.php?txt=11006

Inicialmente, dependiendo del tanque disponible así será la cantidad de biogás producido por el digestor. Los usos para este biogás podrían ser cocinar algunos alimentos, calefaccionar una estancia, iluminar o simplemente para proyectos o experimentos caseros. Para esto último sería muy útil un mechero Bunsen ya que permite regular el flujo de gas y la mezcla de aire-biogás de forma sencilla.

El biodigestor debería construirse de acuerdo a la disponibilidad de recursos y no tratar de hacerlo exactamente con los materiales que mencionaré a continuación. 


\section{Los Materiales y su descripción}

El reactor y la entrada de materiales

- Un tanque o bidón de entre 120 y 220 litros de capacidad. Generalmente son azules con tapa de cierre hermético.

- Tapón de limpieza sanitario (4"): Es una especie de adaptador con tapón enroscable.

- Segmento corto de tubo (4"): Pasa a través de la abertura y conecta el "adaptadotapón" en el exterior con la Reducción en la parte interna del tanque. Debe ser suficientemente corto para permitir que tanto la Reducción como el adaptador-tapón aprisionen la pared de la tapa del tanque y así permitir una mejor sujecion y sellamiento. También se pueden usar bridas sanitarias pegadas con silicona al tanque.

- Reducción PVC de 4" a 3"

- Tubo PVC sanitario (3"): Desde la reducción hasta $5 \mathrm{~cm}$ antes del fondo del tanque. Gráfico 03: Construcción del Biodigestor
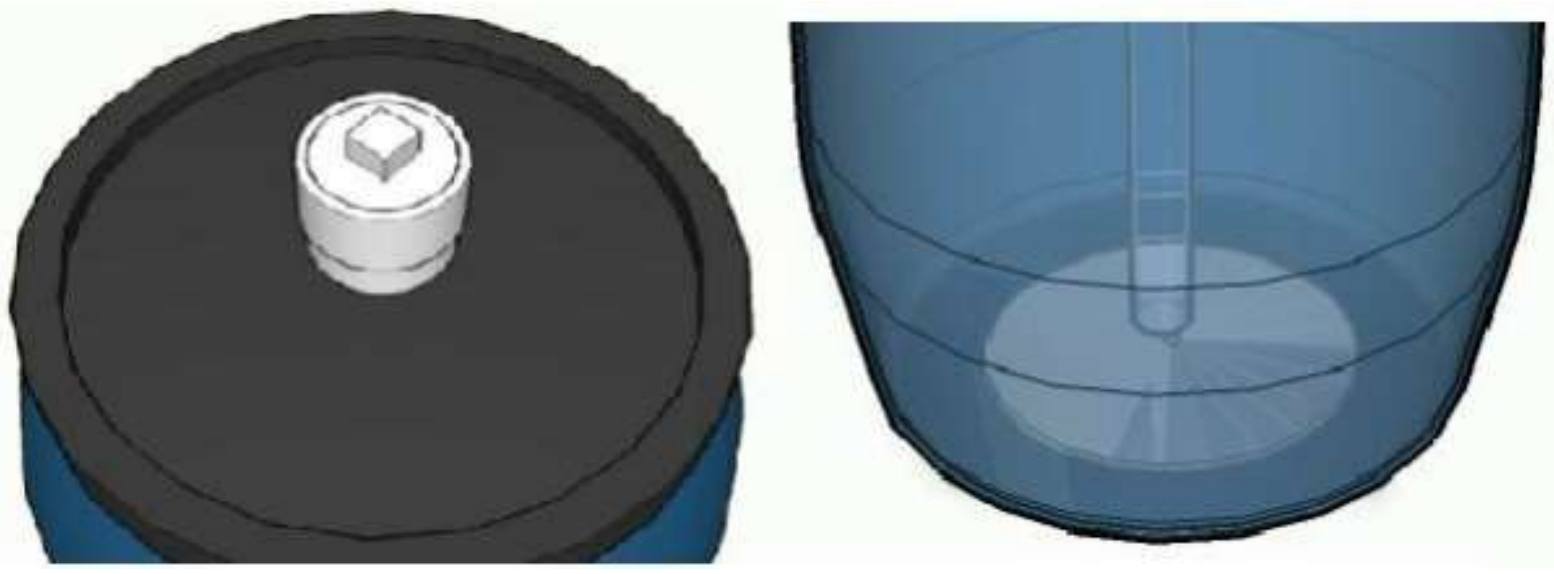

Referencia: https://www.taringa.net/comunidades/eduardoescobar/394908/Biodigestorcasero-de-bidon.html

\section{Para la salida del efluente:}

- Adaptador de tanque (2”)

- Tubo PVC (2") para la tubería de salida del efluente

- 3 Codos PVC (2")

- Adaptador de tanque (1") para conectar la válvula

- Válvula de esfera PVC (1") Para la salida inferior del efluente más pesado.

Para la salida del biogás (en orden):

- Conector de tanque (1/2") 
- Válvula de esfera con roscas (1/2")

- Adaptador para manquera

- Manguera

\section{Para unir las partes y sellar:}

- Soldadura (pegamento) para PVC

- Silicona selladora transparente, ;resistente a hongos!: Para sellar alrededor de las uniones al tanque e impedir filtración.

Al tanque se le realizan dos agujeros laterales y dos en la tapa. Uno en la parte lateral-inferior para la válvula de 1 pulgada; otro en la parte media para la salida de efluente. En la tapa uno será para la entrada del material y el otro para la salida del biogás, siempre del diámetro de la pieza que lo atraviesa.

Para almacenar el biogás se utiliza un depósito de campana flotante, muy fácil de construir con dos bidones; uno grande donde va el agua y otro ligeramente más angosto que se sitúa boca abajo dentro del anterior. La manguera que viene del digestor se introduce al tanque mayor y burbujea de tal forma que el gas sube y queda atrapado en el tanque menor el cual tiene una válvula para la salida del gas con una manguera y una trampa de agua.

\section{Protección del biodigestor.}

- Proteja el Biodigestor utilizando cercos de protección contra animales y niños que podrían dañar el sistema.

- Instale techos de protección que evite la llegada directa de rayos de sol y la caída de animales al foso.

- En épocas de lluvia tape las bocas de entrada y salida del biodigestor, para evitar que penetre el agua.

- Evite también el paso de piedras o sobrantes de pasto.

\section{Conclusiones.}

- El sistema planteado es viable para una finca pequeña donde la población de ganado vacuno y porcino no supere la capacidad del tanque de 220 litros, caso que se decida realizar con una proporción mayor de materia orgánica se deberá construir depósitos de mayor capacidad.

- En cuanto a los costos, los mismos son alentadores tanto para la inversión pública como privada, presentando una clara ventaja en cuanto a la factibilidad de controlar riesgos de pérdidas por construcción y por daño de animales.

- La utilización de biodigestores ofrece grandes ventajas para el tratamiento de los desechos orgánicos de las explotaciones agropecuarias, además de disminuir la carga contaminante de los mismos, extrae gran parte de la energía contenida en el material mejorando su valor fertilizante y controlando, de manera considerable, los malos olores. 


\section{Referencias Bibliográficas}

Acuña Rubio, J. P. (2015). DISEÑO E IMPLEMENTACIÓN DE UN BIODIGESTOR PARA EL. UNIVERSIDAD CENTRAL DEL ECUADOR, 80.

Arce Cabrera, J. J. (2011). Dise; o de un Biodigestor para generar Biogas a partir de desechos organicos. Universidad Politecnica Salesiana, 104.

Casera, E. (2009). Energia Casera. Obtenido de Biodigestor casero de bidón: https://energiacasera.wordpress.com/2009/11/19/biodigestor-casero-de-bidon/

CEDECAP. (2017). BIODIGESTOR DE POLIETILENO: CONSTRUCCIÓN \&. CEDECAP, 15.

Gallo Mendoza, L. (2016). BIODIGESTORES PLÁSTICOS AMPLIABLES PARA LA AGRICULTURA FAMILIAR. INTA EEA Reconquista, 5.

Hernadez, M. (16 de 08 de 2016). ELMOTOR. Obtenido de Cuantos más baches haya, más gasolina ahorrarás: https://motor.elpais.com/tecnologia/amortiguadores-paraahorrar-gasolina/

Hernandez , A., \& Burniol, A. (201676). Tecnica y Tecnologia. Nova Agora. Obtenido de http://www.interempresas.net/Flipbooks/MR/3/pdf/Libro\%20MR3.pdf.

Ibañez, S. (06 de 08 de 2016). ABC Novedades. Obtenido de https://www.abc.es/motor/novedades/abci-amortiguadores-ahorran-combustible-yaumentan-confort-201608121212_noticia.html

Lopez, J. (12 de Enero de 2018). HighMotor. Obtenido de https://www.highmotor.com/refinamiento-sutilieza-caracteristicas-nuevo-bentleybentayga-v8.html

Marti Herrero, J. (2014). IdeassAMÉRICA LATINA. Innovación para el Desarrollo y la Cooperación Sur-Sur, 12.

Martí, A. (03 de Febrero de 2016). Talleres Chosen. Obtenido de https://www.tallereschosenmostoles.es/2016/11/amortiguadores-que-ahorrancombustible.html

Rodriguez Pichon, D. A., \& Garcia Cepeda, A. F. (2017). DISEÑO Y CONSTRUCCIÓN DE UN BIODIGESTOR PARA LA PRODUCCIÓN DE. UNIVERSIDAD DISTRITAL FRANCISCO JOSÉ DE CALDAS, 97.

Rodriguez, D., \& Urbina Bravo , A. (2013). BIODIGESTORES. Programa Regional de Ganadería MAG Grecia, 95.

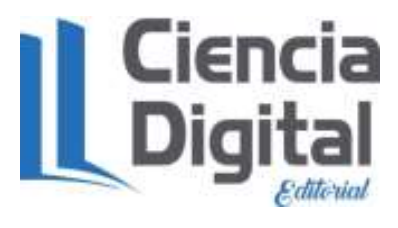




\section{PARA CITAR EL ARTÍCULO INDEXADO.}

Hidalgo Osorio, W., Vásquez Carrera, P., Espinosa Cunuhay, K., \& Morales Tamayo, Y. (2019). Desechos orgánicos que generan gas a través de un biodigestor diseño experimental en la parroquia Guasaganda de la ciudad de la Maná. Ciencia Digital, 3(2.6), 190-205. https://doi.org/10.33262/cienciadigital.v3i2.6.558

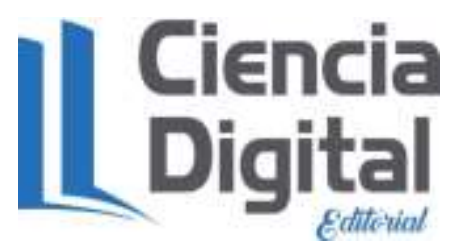

El artículo que se publica es de exclusiva responsabilidad de los autores y no necesariamente reflejan el pensamiento de la Revista Ciencia Digital.

El articulo queda en propiedad de la revista y, por tanto, su publicación parcial y/o total en otro medio tiene que ser autorizado por el director de la Revista Ciencia Digital.
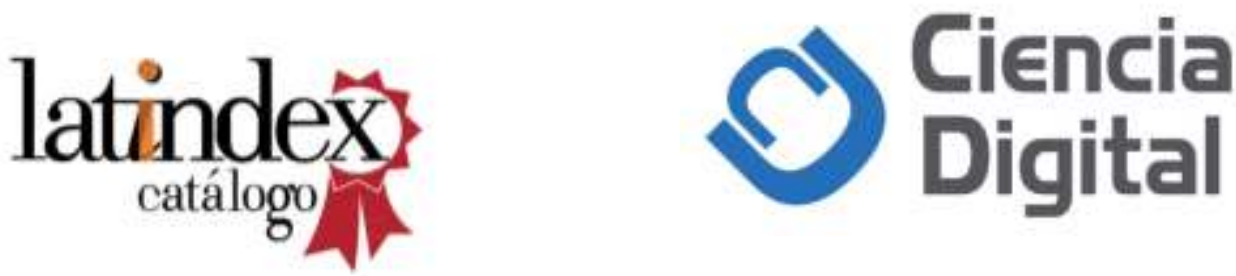